\title{
Consonant Cluster Acquisition by L2 Thai Speakers
}

\author{
Apichai Rungruang ${ }^{1}$ \\ ${ }^{1}$ Faculty of Humanities, Naresuan University, Phitsanulok, Thailand \\ Correspondence: Apichai Rungruang, Faculty of Humanities, Naresuan University, Phitsanulok, Thailand. \\ E-mail: rapichai2002@yahoo.com
}

Received: April 29, 2017 Accepted: June 10, 2017 Online Published: June 13, 2017

doi: 10.5539/elt.v10n7p216 URL: http://doi.org/10.5539/elt.v10n7p216

\begin{abstract}
Attempts to account for consonant cluster acquisition are always made into two aspects. One is transfer of the first language (L1), and another is markedness effects on the developmental processes in second language acquisition. This study has continued these attempts by finding out how well Thai university students were able to perceive English onset and coda clusters when they were second year and fourth year students. This paper also aims to investigate Thai speakers' opinions about their listening and speaking skills, and whether their course subjects enhanced their performance. To fulfil the first objective, a pretest and posttest were launched to measure how the 34 Thai participants were able to identify 40 onset and 120 coda clusters at different periods of time. The statistical findings show that even though their overall scores in the fourth year were higher than those in the second year, there was no statistically significant difference in both major types of clusters $[t=-1.29 ; \mathrm{p}$ value $>0.05$ in onsets; $\mathrm{t}=-0.28 ; \mathrm{p}$ value $>0.05$ in codas]. The Thai participants performed slightly better in onset $(84 \%$ / $86 \%)$ than in coda $(70 \% / 71 \%)$. To complete the second objective of the study, a 24 -item questionnaire was distributed to the participants. The responses indicated positive opinions about their listening and speaking skills and the English courses they took in a four-year study. However, they still had difficulty identifying some English consonant clusters even though those were widely used or found. Finally, most participants claimed that English Phonetics and Phonology Course was one of the significant course subjects instrumental in establishing their fundamental knowledge of how to pronounce English words and develop their listening skill as well.
\end{abstract}

Keywords: English consonant clusters, speech sound perception, L2 speakers

\section{Introduction}

\subsection{Background}

It is believed that the ease or difficulty of acquiring second language (henceforth L2) sounds depends on the influence of L1 or native language of the speakers. Whenever L2 sounds are close or very similar to L1 sounds, those sounds should be easy to acquire. By the same token, if L2 sounds are different from L1 sounds, it is not easy for the L2 learners to acquire the target sounds (Strange \& Shafter, 2008; Munro, 2008; Zampini, 2008). This principle can apply to the consonant cluster acquisition in the sense that learners whose native language has simpler consonant structures than the target language can face some difficulty acquiring it. There is no exception to this when L2 Thai speakers deal with English consonant clusters whose structures are much more complicated than Thai's.

Based on the literature review, a number of Thai and foreign scholars have conducted studies on English onset and coda clusters (Chakma, 2014; Kalra, 2010; Mano-Im, 1999; Padibat \& Cochran, 1997; Pulsup, 1993; Phoprai, 2008; Sarapan, 1990; among others). Most available literature focused on different types of onset and coda clusters. In other words, no single research exists with an extensive investigation on every English onset and coda cluster, particularly to explore consonant cluster acquisition. In addition, even though most researchers did the data collection with either high school students or university students, it is very surprising that far too little attention has been paid to learners' opinions about the impact of the course subjects they took at schools or universities on their language performance, particularly, whether the course subjects ameliorate or deteriorate their listening and speaking performance (Note 1). As a result, this study was needed to fill a knowledge gap and extend the past research.

The present research investigates how native Thai speakers acquire English consonant clusters and their opinions about the English course subjects they took in the four years of undergraduate study. The long term implications 
of this study will impact classroom teaching and learning, researchers, and practitioners. That is, the findings from this study can be applied to classroom teaching and learning by having appropriate activities to promote English consonant cluster acquisition. In addition, researchers will gain a better understanding of English consonant clusters and can conduct this topic with other L2 learners. Finally, practitioners can use the present findings as an initial step to other types of possible phonetic training.

\subsection{Theoretical Framework}

The Markedness Differential Hypothesis (MDH), formulated by Eckman (1977), was chosen since it was one of the phonological acquisition theories that make a connection between native language transfer and language universals. MDH makes the prediction that if language $\mathrm{A}$ has marked structure at a particular point and language $\mathrm{B}$ has at this point unmarked or less marked structure, then speakers of A should more quickly acquire the unmarked structure in B than speakers of B should acquire the marked structure in A. To put it simply, marked structures are difficult to learn, particularly if those in target language (TL) are more marked than those in native language (NL). The MDH goes farther than its predecessor, the Contrastive Analysis Hypothesis (CAH), which claims that the difference between TL and NL can be a barrier to language acquisition. As a result, CAH forms a hierarchy of difficulty to make a prediction of the relative difficulty of a given aspect of the TL. MDH also has this aspect and proposes that not every difference between TL and NL causes learners difficulty. For example, Thai does not have fricatives in its final consonant system. It can be predicted that [s] should be easier to acquire than $[\theta]$ and [ð]. For one important thing, Thai does have an [s] in an initial consonant. The other two interdental fricatives should pose more problem than [s]. In both interdental fricatives, the voiced consonant or [ð] should take longer time to acquire than the voiceless one or $[\theta]$. That is, voiced consonants are more marked than voiceless ones. Phonetically, voiced consonants require more energy to produce to vibrate the vocal folds. Phonologically, the unmarked consonants are more widely found than the marked ones. Thus, MDH takes advantages of the role of $\mathrm{L} 1$ and the notion of markedness. As a result, the researcher proposes the ranking order of English consonant clusters acquired by Thai learners as follows.

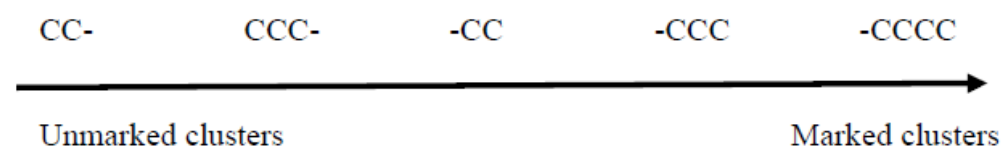

Figure 1. Markedness hierarchy scale

According to the scale, the longer the consonant sequence, the more marked it is. The existence of the longer cluster in a langauge implies the existence of the shorter one, but not vice versa. The shorter one is less marked and more universal than the longer one. It should be noted that unmarked clusters mean or refer to the clusters which are easy to learn or acquire. In contrast, marked clusters refer to the clusters which take longer time to acquire and can be problematic for the learners. Therefore, $\mathrm{CC}$ - is the easiest cluster and tends to reflect high scores in the test. $-\mathrm{CCCC}$ is expected to be the most difficult and problematic cluster. For the sake of convenience, MDH is called the Markedness Theory in this paper. In sum, the Markedness Theory is an effort that linguists try to bridge the gap of human languages. It would be nice if the intricate variety of human language was a commonplace, widely understood in our own and other sound systems when we could unlock why certain sounds in one language were so difficult for other language speakers. This can cause us not only understand each other better, but also acquire other language well.

\subsection{Literature Review}

As mentioned earlier, a number of scholars believe that the second language sounds are always influenced by the mother tongue sounds. In other words, L1 has an impact on L2 sounds when L2 learners acquire new sounds. To see a clear picture of how English consonant clusters were treated by speakers of other languages, this part presents five related studies regarding English consonant cluster acquisition.

Chen (2011) did a study with nine Taiwanese students who learned English as a foreign language. Only two and three-member English onset clusters were tested. In principle, consonant clusters do not exist in the Chinese phonological inventory. Thus, it was assumed that the participants should have some difficulty acquiring the more marked structure (the three-member clusters) than the less marked one (the two-member clusters). The findings revealed that Taiwanese participants made more changes in the more marked clusters than the less 
marked ones. The participants employed either a consonant deletion or a vowel insertion as repair strategies to modify the foreign sounds to fit their native language inventory. As a theoretical framework, Markedness Differential Hypothesis and Interlanguage Structure Conformity Hypothesis were employed to account for sound changes. The findings showed that both theories held true in most cases.

Another study by speakers whose native language did not have onset consonant clusters was conducted by Choi (2016). He focused his attention on the acquisition of English /s/ + consonant onset clusters by Korean speakers. Divided into low and high language achievement groups, twenty-eight secondary school students took the test. The researcher predicted that students would insert a vowel as a repair strategy to fit their phonological inventory. Based on the Sonority Sequencing Principle (SSP), /s/+ nasal clusters would be more difficult than $/ \mathrm{s} /+$ liquid clusters for the Korean speakers. The findings showed that only the low language achievement group employed a vowel insertion strategy. The SSP did not work well in the study. That is, $/ \mathrm{s} /+$ liquid clusters were more problematic since Korean does not have the $/ 1 /$ and $/ \mathrm{r} /$ distinction which was found in English. In terms of three-member clusters, /s/+ stop + liquid posed the biggest problem for the participants.

Besides onset consonant clusters, final consonant clusters were another interesting topic carried out by Yuliati (2014). Her focus was on how Bahasa Indonesian speakers dealt with English final consonant clusters. The previous studies with Indonesian learners were summarized to reflect the acquisition of English coda clusters. That is, final consonants clusters could be devoiced (e.g. voiced consonant [b], [g] were replaced by the voiceless $[\mathrm{p}],[\mathrm{k}]$.$) . Obstruent consonants were the most popular devoicing ones. Deletion was another repair$ strategy, particularly sonorous consonants. However, this was not always the case. In English regular plural forms and past forms, [t], [d], [s], and [z] were always omitted. In the three-member coda clusters, they preferred to delete one of them to do the devoicing. Since her study was a summary of previous studies, no theoretical framework was introduced or employed to explain why Indonesian speakers prefer one strategy to another.

A study of coda consonant cluster acquisition was also found in Wiltshire (2006). Twenty-five Indian speakers participated in the study. They had five different L1 backgrounds with different sound inventories. That is, Angami, Ao, and Mizo do not allow consonant clusters, but Gujarati and Hindi have consonant clusters in their phonological system. All participants were asked to read a word-list and sentences to elicit their production accuracy in two-member final clusters. The findings mirrored that speakers of the L1s without consonant clusters deleted more often than those of L1s with consonant clusters. However, consonant cluster reduction was hierarchical. That is, the fricative-stop clusters were more deleted than others. Nasal-stop and stop-fricative clusters were rare for all L1 backgrounds. The researcher employed Optimality Theory (OT) as a framework of analysis. Devoicing in obstruents and fricatives was set as one of the markedness constraints. MAX-IO (C) was used as a faithfulness constraint to prevent any consonant deletion.

Besides speakers in Asia, a study by Spanish speakers was done by Jurado (2005). Divided into two major groups (high and low language proficiency), eight participants (four in each group) were asked to read sentences and individual words to test their pronunciation accuracy. Consonant clusters in Spanish are much less complicated than those in English. To be more precise, only two-member onset clusters are found; coda clusters are rare (only from word-borrowing). Like other previous studies, it was predicted that the participants would simplify difficult L2 sounds to fit their native language sound structure. It was predicted that two repair strategies, namely a consonant reduction and a vowel insertion would be employed. The finding showed that the participants employed more vowel insertion in the onset clusters, particularly when the first consonant was an /s/ A consonant reduction was found in English coda clusters. Markedness Differential Hypothesis and Contrastive Hypothesis accounted for these sound changes. However, in some cases the two theories did not hold true. For example, the sequences of plosive+plosive (slept, fact) were supposed to be difficult, but the participants did well. Another consonant sequence was $\mathrm{C}+/ \mathrm{s} /$, as in 'milks' and 'cups'. However, the researcher did not provide any reason why the participants performed well in particular marked clusters.

In conclusion, most empirical studies reflected that English consonant clusters pose some problems for L2 learners to acquire. To account for the causes and to make a prediction of difficulty, many theories were employed, namely Markedness Differential Hypothesis, Interlanguage Structure Conformity Hypothesis, Sonority Sequencing Principle, Optimality Theory, and Contrastive Hypothesis. These theories reflect that a notion of markedness as a part of the theories plays a significant role in accounting for consonant cluster acquisition. The present study also employed this notion as a theoretical framework. However, what made the current study differ from the previous literature was twofold. First, all possible English consonant onset and coda clusters were examined. The previous studies limit themselves to either onset or final consonant clusters. Second, the opinions about the subject courses from the university participants were taken into consideration. In other words, the Thai university students' opinions regarding their listening and speaking skills and English subject 
courses they took during their four-year study were investigated in the present study.

\subsection{Research Objectives}

The research objectives are twofold. The major objective was to investigate Thai speakers' perception of English onset and coda clusters. To be more specific, the research explored how Thai university students were able to perceive English initial consonant and final consonant clusters during their four-year degree study. The secondary objective was to examine the participants' opinions about their listening and speaking skills and how English courses they took in the four-year study played a role in their listening and speaking performance.

\subsection{Research Questions}

This paper addressed the following questions:

1) To what extent were Thai university students able to perceive English onset and coda clusters during their four-year study?

2) What were Thai university students' opinions about their listening and speaking skills, and how did the previous English courses they took in four years have an impact on their listening and speaking skills?

\section{Research Methodology}

\subsection{Participants}

Thirty-four English major participants were selected on the basis of a degree of homogeneity of their study to the research objectives. All participants were aged between 20 and 21 at the beginning of the study (when they were in the second year of their degree study). Not only did all participants have no overseas experience in any English speaking countries, but they also had no history of hearing impairments or speech disorders at the time of the present study.

\subsection{Tokens}

All tokens were collected from many previous studies and they were divided into two groups: onset clusters and coda clusters. More details are below.

\subsubsection{Onset Clusters}

Forty tokens were English onset clusters. They consisted of two major sub-groups: 33 two-member onsets, and 7 three-member onsets. Below are some of them.

Two-member onset clusters (CC-)

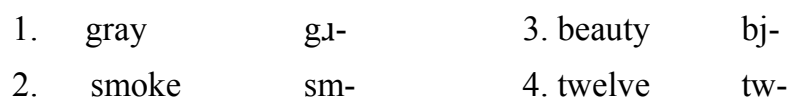

Three-member onset clusters (CCC-)

$\begin{array}{lllll}\text { 1. } & \text { string } & \text { stu- } & \text { 3. scrape } & \text { sku- } \\ \text { 2. } & \text { spring } & \text { spl- } & \text { 4. spew } & \text { spj- }\end{array}$

\subsubsection{Coda Clusters}

One hundred twenty tokens were English coda clusters. They were divided into three sub-groups: 64 two member codas, 49 three member codas, and 7 four member codas. Some of them are listed below.

Two-member coda clusters (-CC)
1. bulb
$-\mathrm{lb}$
3. lisp
$-\mathrm{sp}$
2. eighth
$-\mathrm{t} \theta$
4. seemed
-md

Three-member coda clusters (-CCC)

$\begin{array}{llll}\text { 1. helps } & - \text { lps } & \text { 3. camps } & -m p s \\ \text { 2. exempt } & -\mathrm{mpt} & \text { 4. sphinx } & -\mathrm{yks}\end{array}$

Four-member coda clusters (-CCCC)

$\begin{array}{llll}\text { 1. thousandths } & -n d \theta s & \text { 3. texts } & \text {-ksts } \\ \text { 2. twelfths } & - \text { lf } \theta \mathrm{s} & \text { 4. prompts } & \text {-mpts }\end{array}$

The number of tokens can be summarized as follows. 


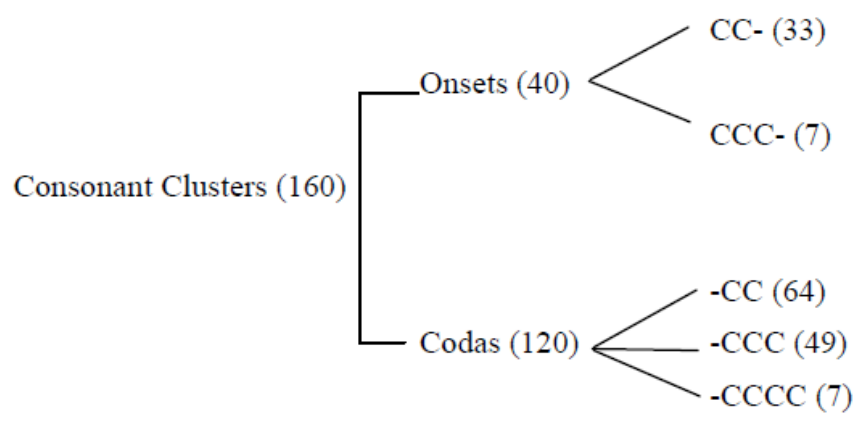

Figure 2. The token classification in this study

\subsection{Research Instruments}

Two research instruments were employed in this study. One was a perception test; the other was a questionnaire. Below are details about both instruments.

The perception test was carried out twice to measure how well students were able to perceive English clusters at a different period of time. One (henceforth 'the pretest') was given when the students were in the second year; the other (henceforth 'the posttest') was conducted when they were in the fourth or final year of the study. To put it simply, both tests were the same test, but the participants took the two tests at a different period of time. Generally, the tests based on multiple choice items consisted of 3 distractor questions, 40 English onset cluster questions, and 120 English coda cluster questions. As distractors, test questions from 1-3 were not calculated since they were used to reduce nervousness or excitement when the test takers started doing the tests. Thus, the test questions from $4-164$ were the major focus of the study; the total target number of test items was 160 . To make the tests measure participants' speech sound perception, an American native speaker was asked to be tape-recorded his speech sounds. In each test item, he pronounced the target tokens twice and the researcher saved all test questions on a laptop computer. Then, all 34 participants were scheduled to sit in a sound proof-room. Individual participants were presented with a task explanation written in English and were orally informed in Thai as well to ensure they obtained exactly the same instructions. They were told to listen carefully to each word or token, then circled the best answer from the four choices (a, b, c, and d). It took them 20 minutes each to complete this task.

The second instrument was a 24-item questionnaire with five Likert scales (strongly agree, agree, uncertain, disagree, and strongly disagree). The participants chose one of the five scales which fitted their opinions. The questionnaire was designed to investigate the participants' opinions about English listening skill, speaking skill, how English courses that they took in four years played a role in their speaking and listening performance, how they dealt with English consonant clusters, and whether they realized the interrelationship between listening and speaking skills. To be precise, the questionnaire questions were divided into six major parts. The first five parts (Parts A-E) provided quantitative data results; the final part (Part F) led to qualitative data findings. Below are details about the six parts.

Part A (Questions 1-4) coped with participants' speaking skill.

Part B (Q 5-8) focused on participants' listening skill.

Part C (Q 9-12) covered how English courses played a role in their listening and speaking skills

Part D (Q 13-16) examined sound structure, particularly English consonant clusters.

Part E (Q 17-20) measured the relationship between participants' listening and speaking skill.

Part F (Q 21-24) included four open-ended questions which allowed the participants to express their opinions about the courses and factors that bettered their listening and speaking skills. This part required the participants to write their answers on a paper sheet.

To avoid any language barrier and ensure a clear understanding of the questions, all questions were asked in the participants' mother tongue (Thai). The questionnaire was distributed immediately after the participants completed the posttest on the same day.

\subsection{Research Validity and Reliability}

In the pretest and posttest, all tokens were checked by two phonetic instructors in the form of IOC (Item 
Objective Congruence Index) to establish content validity. Then, a few words were changed and replaced to fit the purposes of the study. In terms of the questionnaire, all the question items were read and commented on by a university professor who held a Ph.D in linguistics. The suggestions and comments were employed to correct the question items to make the questions clear and well-written and fit the objective of the study. Next, a pilot project was launched with 20 students who were not in the experimental group to test how the perception tests worked well with them. To ensure that the 24 question items in the questionnaire were not too many to make the participants fatigued after taking the posttest, but were long enough to guarantee adequate measurement of what intended to investigate, the same pilot group completed the questionnaire. To draw a picture of the research instrument development process, see Figure 3.

Designed research instruments by considering research questions and objectives

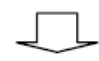

Had the instruments evaluated by experts

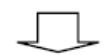

Improved the instruments

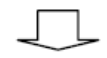

Tried out the instruments with someone who met the criteria for being the participants

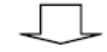

Improved the instruments

Figure 3. Research instrument development process

\subsection{Data Collection and Procedure}

As mentioned earlier, a data collection process was done twice at a different period of time with the same group of participants. That is, the first time the data was collected was when the participants were second-year students in 2013. The second time the data collection was completed was when they were four-year students in 2015. So, the time range may make it possible to echo their English consonant cluster acquisition. The researcher had the participants take the same test for two main reasons. First, they took the test at different time periods. Therefore, the two-year gap could remove any familiarity with the test. Second, to see an obvious change in their consonant cluster acquisition, the same test should be employed to compare the relative performance of the participants. As stated earlier, the researcher also distributed the questionnaire to examine the participants" opinions about their listening and speaking skills, and the previous English courses they took in four years. The questionnaire was only carried out when the participants were fourth year students to fit the purpose of the study in that they were in the final year of the study and had taken many English courses. When they were fourth year students, the researcher had the participants take the posttest first. After doing the posttest, they were immediately asked to complete the questionnaire. They spent approximately 7-8 minutes finishing all 24 questions.

To visualize the data collection procedure and analysis, see Figure 4.

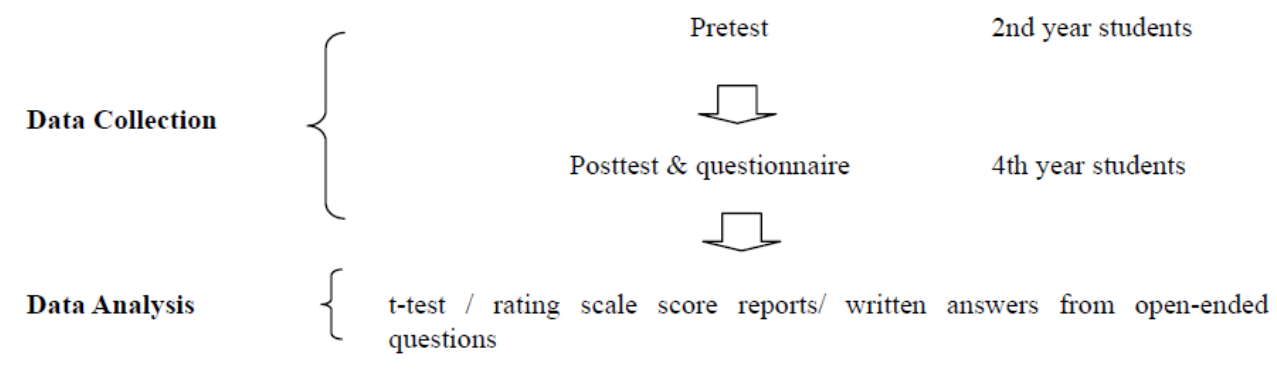

Figure 4. Data collection process and analysis 
After all students completed the pretest and posttest, the researcher did the grading. Finally, a t-test of dependent samples were employed to measure whether statistically significant difference between the two tests existed or not. In terms of the questionnaire, the researcher transferred the responses from rating scale question items (questions 1-20) into a computer software program to analyze the questionnaire responses. As stated earlier, open-ended question items from 21-24 required the participants to write their answers in text format. The researcher grouped the answers with their stated reasons. In this part, the answers were varied since all four questions allowed the participants to provide multiple answers.

\section{Results}

This part covers the findings from the pretest and posttest and questionnaire results to answer the two research question as below.

3.1 First Research Question: To what extent were Thai university students able to perceive English onset and coda clusters during their four-year study?

Table 1. Dependent t-test in onset clusters (40 tokens) and coda clusters (120 tokens) (Rungruang \& Glover, 2017)

\begin{tabular}{lllll}
\hline Types of tests & Mean & SD & t & p value \\
\hline Onset pretest $\left(2^{\text {nd }}\right.$ year students) & 34.50 & 2.96 & & \\
Onset posttest ( $4^{\text {th }}$ year students) & 35.38 & 2.41 & & \\
Pretest \& posttest comparison & 0.88 & 3.97 & 1.29 & 0.20 \\
& & & & \\
Coda pretest ( $2^{\text {nd }}$ year students) & 84.29 & 10.39 & & \\
Coda posttest (4 $4^{\text {th }}$ year students) & 85.08 & 11.24 & & 0.78 \\
Pretest \& posttest comparison & 0.79 & 16.44 & 0.28 & \\
\hline
\end{tabular}

Table1 illustrates an overall picture of the participants' perception performance. A dependent t-test was run to analyze onset and coda cluster acquisition. In the onset clusters, there was no significant difference between the two tests $(\mathrm{t}=1.29 ; \mathrm{p}>.05)$. By the same token, the coda clusters did not show any statistically significant difference between the pretest and the posttest $(t=0.28 ; \mathrm{p}>.05)$. Therefore, the statistical findings provide evidence that no progress was found in both types of consonant cluster acquisition over a four-year study. To consider the quantitative findings in detail, the 40 English onset clusters and 120 coda clusters are presented as follows.

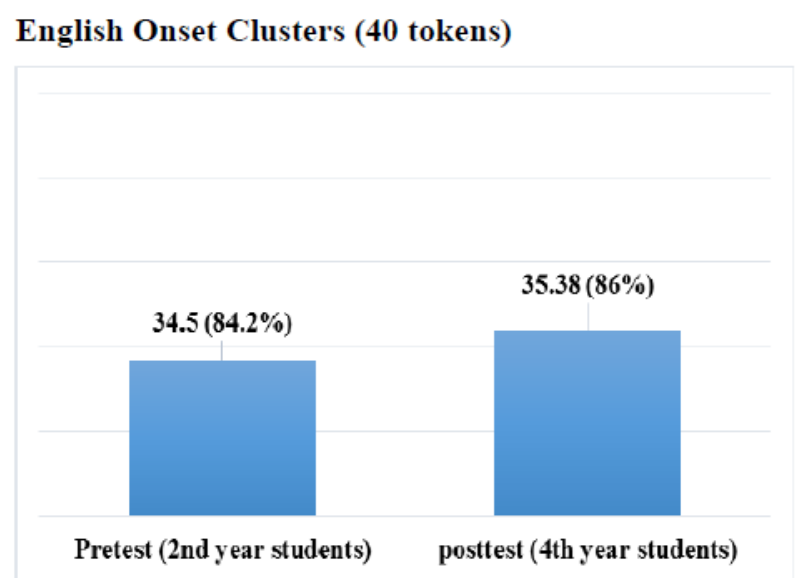

Figure 5. Mean scores on English onset cluster performance

Figure 5 presents mean scores on English onset cluster performance. It appears that there was slight difference 
between the two tests. That is, the mean scores when they were in the second year and fourth year were 34.5 (84\%) and $35.38(86 \%)$, respectively. However, these findings were still too sketchy to see the students' performance in-depth. Therefore, Table 2 draws a clearer picture of what happened in the two and three-member onset clusters. The statistical analysis represents three performances. If their mean score in the 2 th year was better than that in the 4th year, it was a negative performance. If it was the other way around, a positive performance was made. Whenever the mean scores from the two tests were the same, it was regarded as a relatively neutral performance. In Table 2 below we can see that the two-member clusters revealed more negative performance ( $43 \%$ ) than neutral and positive ones ( $27 \%$ and $30 \%$, respectively). On the other side of the scale, the three-member clusters reflected more positive performance (42\%) than neutral and negative ones with equal percentages (29\%). It is very interesting to find out why the Thai participants did better in the marked structure (CCC-) than the unmarked one (CC-). Does this go contrary to the Markedness Theory? These issues will be investigated in the discussion part.

Table 2. A summary of onset cluster performance (Rungruang \& Glover, 2017)

\begin{tabular}{lllll}
\hline $\mathrm{N}=40$ & Number of tokens & Positive & Neutral & Negative \\
\hline $\mathrm{CC}-$ & 33 & $10(30 \%)$ & $9(27 \%)$ & $14(43 \%)$ \\
$\mathrm{CCC}-$ & 7 & $3(42 \%)$ & $2(29 \%)$ & $2(29 \%)$ \\
\hline
\end{tabular}

Now, let's consider how the participants handled coda clusters.

English Coda Clusters (120 tokens)

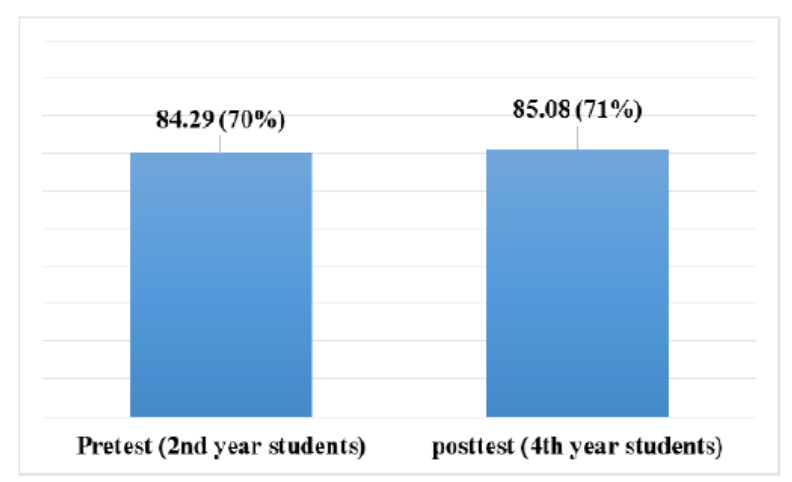

Figure 6. Mean scores on English coda cluster performance

Like Figure 5, Figure 6 shows only a slight positive change in mean scores between the two tests. That is, the mean scores in the second year and fourth years were $84.29(70 \%)$ and $85.08(71 \%)$, respectively. It looks like the length of time in their study program resulted in no performance difference. Table 3 exhibits more details in the three major types of coda clusters. The findings provide a reverse result when compared to those in the onset clusters. More precisely, they showed very positive performance in the two and three-member clusters $(42 \%$ and $43 \%$, respectively). Low percentages were found in negative performance (13\% and $12 \%$, respectively). But nearly $50 \%$ of their performance showed no progress between the two tests. In the most marked structure or the four-member coda clusters, the participants had difficulty perceiving them. Their negative performance was more dominant than the other two types of performances. That is, negative, positive, and neutral performances were $57 \%, 43 \%$, and $0 \%$, respectively. Again, the explanation for these findings will be discussed in the discussion part. 
Table 3. A summary of coda cluster performance (Rungruang \& Glover, 2017)

\begin{tabular}{lllll}
\hline $\mathrm{N}=120$ & Number of tokens & Positive & Neutral & Negative \\
\hline$-\mathrm{CC}$ & 64 & $27(42 \%)$ & $29(45 \%)$ & $8(13 \%)$ \\
$-\mathrm{CCC}$ & 49 & $21(43 \%)$ & $22(45 \%)$ & $6(12 \%)$ \\
$-\mathrm{CCCC}$ & 7 & $3(43 \%)$ & 0 & $4(57 \%)$ \\
\hline
\end{tabular}

\subsection{Second Research Question}

What were Thai university students' opinions about their listening and speaking skills, and how the previous English courses they took in four years had an impact on their listening and speaking skills? The second research question aimed to explore students' opinions about their language performance and English courses during their four-year study. This part considers two aspects. The first one covers the questionnaire items 1-20 to provide quantitative findings. The second one deals with the questionnaire items 21-24 to provide qualitative findings.

\subsubsection{Questionnaire Items 1-20 (Parts A-E)}

Below is a summary of the five parts in the questionnaire items with five scales (strongly agree, agree, uncertain, disagree, and strongly disagree). A questionnaire score report from question items 1-20 can be seen in Appendix B.

Part A: Questions1-4 coped with participants' speaking skill. The level of the participants' opinions was 'strongly agree' and 'agree' with the question items. In other words, they showed positive responses regarding their speaking skill.

Part B: Questions 5-8 were about participants' listening skill. They reflected positive responses (strongly agree -agree) with their listening skill. Only question 6 (I think my listening skill is better than the other three language skills—speaking, reading, and writing) revealed a neutral response.

Part C: Questions 9-12 covered how English courses played a role in their speech perception and production. This was the only part that illustrated highly positive opinions to questionnaire items. The participants strongly agreed that all courses were so helpful and beneficial for their listening and speaking skills.

Part D: Questions 13-16 considered English sound structure, particularly English consonant clusters. Samples of tokens to mirror the participants" knowledge about sound structure were used. They had positive ideas about how they could handle the English sound structure. Interestingly, question 15 (the terms "can" and "scan" share the same number of syllable) provided an unclear-cut answer (uncertain response). This issue will be discussed in the next part.

Part E: Questions 17-20 measured the relationship between participants' speaking and listening skills. Unlike the previous parts, Part E expressed uncertain responses when dealing with the interrelationship between their speaking and listening skills.

\subsubsection{Questionnaire Items 21-24 (Part E)}

This part included 4 open-ended questions regarding the English course subjects that bettered their speaking and listening skills and factors that sharpened their speaking and listening skills. More details can be seen in Appendix C. In Question 21, when asked to identify the English course subjects which enhanced their pronunciation and speaking skill the most, 25 participants (out of 34) claimed that Phonetics and Phonology Course helped them to learn the principles and practices of how to pronounce English words correctly. Seven participants believed that the dialogs and real life situations in the textbooks in Conversation and Discussion Course helped them learn to speak English better. Five participants stated that Oral Presentation and Public Speaking Course was another good course that required them to speak the target language in class. In Question 22 , they stated the factors that improved their pronunciation and speaking skill. 12 participants believed that practice was the key to success; in other words, practice makes perfect. Nine people revealed that communicating with native or foreign speakers enhanced their speaking skill. Another nine participants claimed that watching movies and listening to music in English was useful to their speaking skill. Interestingly, other listening activities such as listening to either news or native speaker dialogs and conversation was helpful as well. In Question 23, when asked to state the course that bettered their listening skill the most, most of them (17 participants) mentioned that Conversation Course was considerably beneficial to their listening skill. Four participants stated that Oral Presentation and Public Speaking Course was helpful. Surprisingly, four participants 
chose Phonetics and Phonology Course as another good course that enhanced their listening skill. Finally, Question 24 asked the participants to pinpoint the factors that advanced their listening skill. Fifteen participants cited that watching movies was very advantageous to understand English. Eight participants identified that practicing listening very often also helped their listening skill improve. A few participants considered that having phonetic knowledge could be a factor in helping them improve their listening skill.

\section{Discussion}

The discussion part focuses further on finding out which clusters students identified well and which ones they did poorly on and finally, how the findings fit the theoretical framework, the Markedness Theory. The final part deals with what the participants thought about their language skills, some English consonant structures, and whether some courses they took in the four-year study program enhanced their listening and speaking performance.

\subsection{Onset Clusters}

Thai participants showed an outstanding performance since their mean scores in both pretest and posttest were relatively high ( 34.50 or $84 \%$ and 35.38 or $86 \%$, respectively). At this point, mean scores from the two tests will be addressed by means of square brackets. The first and second numbers in the brackets refer to the scores from the pretest and those from the posttest, respectively. In general, the participants had an impressive performance in many marked tokens. To be more specific, five out of seven three-member tokens, which were regarded as the most marked tokens in onsets for Thais, illustrated a high rate of accuracy. Some of them were skw- [33/34], stu[34/34], etc. Two of them had low scores in the posttest; they were spl-[30/27] and spj- [33/28]. One question that needs to be asked is: why did the Thai participants have high accuracy in marked tokens? Based on the Markedness Theory, the findings should be the other way around. That is, they should have had low scores in these tokens or CCC-. It seems that the findings were not congruent with the theory. The researcher posits that the tokens that were used might be too familiar to the participants. Some of the seven tokens, namely 'spray', 'spring', 'string', and 'squeeze' were widely found in everyday conversation in the Thai context. In other words, these were English loanwords in Thai. As a result, they were not marked forms for the participants. What happened with the two-member onset clusters? By and large, only ten initial consonant clusters are found in Thai. They are: kr-, kl-, kw-, $\mathrm{k}^{\mathrm{h}} \mathrm{r}-, \mathrm{k}^{\mathrm{h}} \mathrm{l}-, \mathrm{pr}-, \mathrm{pl-}, \mathrm{p}^{\mathrm{h}} \mathrm{r}-, \mathrm{p}^{\mathrm{h}} \mathrm{l}-$, and tr-. Thus, Thai has many fewer numbers of two-member onset clusters in their phonological system than the English counterpart. Needless to say, L2 Thai learners had a hard time perceiving many two-member clusters, particularly when the tokens consisted of [x] and [1]. It should be noted that phonetically the Thai $[r]$ and the English counterpart $[\mathrm{l}]$ are different sounds. One is a trill $[\mathrm{r}]$ as a prestige variant (Phootirat, 2012); the other is a rhotic [ı]. Ladefoged and Maddieson (2005: 216) define [r] as an 'alveolar trill' and [ $\mathrm{x}]$ as an 'alveolar approximant'. Those questionable clusters were, pl- [32/29], pu- [30/26], kl[28/26], fl- [29/28], f.-30/28], bl- [33/28], and br- [20/21]. For the most part, the participants had lower scores in the posttest when we compared to those in the pretest. Worse, some tokens had very low scores in both tests even though the posttest score was slightly higher than those in the posttest such as k. - [17/20]. It is very surprising that pl- and kl- reveal regressive performance although both onset clusters are found in Thai, as in pl- as in [plaa] 'fish', [klai] 'loose or relax'. Previous research studies from Thai scholars on [1] and [r] by Phootirat (2012) and Chunsuvimol (1996) also confirm that these two consonants in singlet or complex onsets are very problematic for Thai speakers. Sometimes Thai people replace one for another; many times they drop the [1] and $[\mathrm{r}]$ in consonant clusters such as [plaa] $\rightarrow$ [paa] 'fish', [prik] $\rightarrow$ [pik] 'chili”. Not surprisingly, Thai participants had a difficulty identifying English clusters with [1] and [x] above. As mentioned above, the Thai $[\mathrm{r}]$ and the English counterpart $[\mathrm{l}]$ are different. The findings reflect that the problematic $[1]$ and $[\mathrm{r}]$ in Thai had an influence on the perception in the English [1] and [r] as well. Interestingly, pj- in the term 'pupil' shows the lowest scores [5/4] in both pre and posttests in the onset cluster part. What causes this phenomenon? It is very possible that this term is pronounced as [pju.pəl], which is very different from its spelling. Thai participants were trapped by its spelling and might expect to hear [pju.pil] or [pju.pil] instead. Thus, only a few students could identify this token. It should be noted that although students did not have an opportunity to see the target tokens while listening and trying to identify the sounds, they had a chance to see all four choices before making a decision. Thus, the spelling from the four choices could influence their decision. It is true that $\mathrm{Cj}$ - does not exist in Thai. Thus, the term 'pupil' had low scores. However, it is not always the case since counter examples were found. Those were 'mute' [mj-], 'new' [nj-], 'queen' [k $\mathrm{k}_{\mathrm{h}-]}$, 'beauty' [bj-] 'view' [vj-], 'few' [fj-], and 'huge' [hj-]. The scores were very high scores between 30-34 in the pretest and 33-34 in the posttest. Again, the researcher propose that Thai participants were very familiar with those words. 


\subsection{Coda Clusters}

The quantitative findings in this part were very striking in several ways. First, coda clusters were not found in Thai. How did L2 Thai speakers handle them? Second, was the findings compatible with Markedness Theory? In other words, did the four-member coda clusters illustrate the most difficult ones for the Thai participants? Third and finally, how did the participant deal with [1] and [s] in target tokens? Did they still pose the problems to the participants?

How did Thai participants cope with the coda clusters? When looking back at Table 3, statistical findings signified that Thai speakers did not do well in the coda clusters. Their positive progress was lower than $50 \%$ in all three major types of coda clusters. Nearly $50 \%$ showed neutral progress. Did the findings fit the theory? To a certain extent, the theory worked well for the four-member clusters. That is, high negative performance was found in this type of cluster at nearly $60 \%$. Were the [1] and [x] still problematic for the participants? To answer the final question, let's consider Table 4 before answering the [1] and [ $\mathrm{x}]$ question.

Table 4. Poor and impressive performance in coda clusters (Rungruang \& Glover, 2017)

\begin{tabular}{|c|c|c|c|c|}
\hline Types of coda & Poor performance & & High performance & \\
\hline \multirow{4}{*}{$-\mathrm{CC}$} & begged [-gd] & {$[5 / 5]$} & bark $[-\mathrm{sk}]$ & {$[33 / 33]$} \\
\hline & sharp [-rp] & {$[6 / 6]$} & turn $[-\mathrm{sn}]$ & {$[33 / 33]$} \\
\hline & $\operatorname{marsh}[-\mathrm{\lambda} f]$ & {$[3 / 9]$} & left $[-\mathrm{ft}]$ & {$[35 / 33]$} \\
\hline & $\operatorname{march}[-\mathrm{xt} f]$ & {$[6 / 6]$} & & \\
\hline \multirow{4}{*}{$-\mathrm{CCC}$} & depths [-pes] & {$[7 / 7]$} & helps [-lps] & {$[33 / 33]$} \\
\hline & midst [-dst] & {$[7 / 10]$} & ends $[-n d z]$ & {$[34 / 33]$} \\
\hline & sevenths $[-n \Theta s]$ & {$[6 / 12]$} & next [-kst] & {$[34 / 31]$} \\
\hline & kilns $[-\ln z]$ & {$[10 / 10]$} & & \\
\hline \multirow{4}{*}{$-\mathrm{CCCC}$} & thousandths [-ndes] & {$[10 / 8]$} & \multirow[t]{4}{*}{$*_{\text {glimpsed }}$ [-mpst] } & {$[33 / 16]$} \\
\hline & prompts [-mpts] & {$[9 / 19]$} & & \\
\hline & texts $[-k s t s]$ & {$[10 / 20]$} & & \\
\hline & sculpts [-lpts] & {$[19 / 23]$} & & \\
\hline
\end{tabular}

Once again, in the square brackets, the first numbers refer to the pretest scores and the second numbers are the posttest scores. Table 4 shows that Thai speakers had difficulty dealing with coda clusters, particularly when the last members were fricatives, namely $\left[\int, \mathrm{t} f, \mathrm{z}, \mathrm{s}\right]$. However, this was not always the case because they had a good performance in certain tokens ending with fricatives, as in 'helps' and 'ends'. In principle, fricatives in consonant final position are marked consonants because they do not exist in Thai. The two fricatives, specifically an interdental fricative $[\theta]$ and an alveolar fricative [s] in the last two members as in 'sevenths', and 'depths', mirrored uphill tokens to perceive. It appears that fricatives reflect their poor performance. However, why did Thais perform well in some tokens with fricative ending? The researcher argues that Thai speakers might be in the process of crossing over the target sounds, which can be called interlanguage. To put it simply, they could identify some fricatives, but not all fricative tokens. They were intermediate between native and target language. Notice that $[1]$ and $[x]$ were found in both high and poor performance. The findings were still inconsistent. The

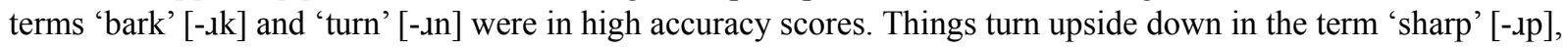
'marsh' [-15], and 'march' [-1tf]. Only [1] showed a low score in the term 'sculpts' [-lpts]', but it provided a high score in 'helps' [-lps]. Again, the findings in [1] and [1] did not provide a clear-cut answer whether they were truly problematic or not. Finally, the theory holds true when -CCCC did not reveal a high-quality performance by the Thai participants. Thai speakers could not handle the most complex marked tokens well. Only three out of seven four-member coda clusters (43\%) showed some improvement; they are -mpts [9/120], -lpts [19/24], -ksts [16/21]. The other four coda clusters (57\%) illustrate a negative improvement. There was no neutral progress. 
Surprisingly, the highest score went to the term 'glimpsed'[-mpst] when 33 second-year students could perceive it, but the score dropped when only 16 fourth year students were able to identify it. The researcher purposes that to discover the reasons or the causes for this is not easy because of the nature of the perception test, as a source of quantitative information. In other words, to use only one instrument to analyze the acquisition is inadequate to gain an in-depth understanding. Further qualitative data collection is required to determine exactly how they handled this token.

\subsection{Questionnaire}

The discussion in the questionnaire findings is divided into two parts. The first part covers the first 20 questions in order to interpret the scores for each question. Their responses were ranked in form of ordinal data measured on five attitude continuums of Likert scale (strongly disagree, disagree, uncertain, agree, and strongly agree). The second part was about the last four open-ended questions. Responses to the open-ended questions were coded to find out which English courses helped them grow and what factors improved their speaking and listening skills. In Parts A and B (Questions 1-8) most participants illustrated positive opinions about their speech production and perception. In other words, the Likert's interpretation score range used was 'strongly agree' to 'agree'. Only Question 6 reflected their own listening competence when they were asked if they believed that their listening skill was better than the other three language skills (writing, speaking, and reading). They were not certain about their listening ability. Unlike Parts A and B, Part C (Questions 9-12) revealed highly positive opinions about the English courses and whether they were helpful for their listening and speaking skills. When the participants were asked to identify the number of syllable and consonant clusters, their answers in these parts were inconsistent. That is, they agreed that they were able to identify the number of syllables (Question 13). The participants had a positive opinion when they were asked whether they could identify the consonant clusters from the given pairs (again/against \& tea/tree). The first pair (the terms again/against) examined their coda cluster identification; the second pair (tea/tree) tested their onset cluster identification. Interestingly, in Question 15 when asked if they could judge whether "can" and "scan" shared the same number of syllables, their response was neutral. This question was a sophisticated one since it tested not only the number of syllables, but also a type of consonant clusters. In other word, the term "scan" was shown to inspect if the participant realized that it had an onset cluster [sk-]. However, in Question 16 when asked to identify if the terms "bet" and "best" shared the same number of syllable or not, they had a correct and clear-cut response to this questions. It looked like they felt more comfortable in handling a final consonant cluster than an initial consonant cluster. Nonetheless, it is too soon to draw a conclusion with only a few tokens. For one important thing, Thais employ a number of English loanwords in their daily life. Since [sk-] does not exist in the Thai phonological system, what Thai people do is to insert a vowel after [s]. So, they pronounce this term in the Thai context as [sakæn]. The term "stamp" is another one that Thai people widely use in their daily Thai conversation. They pronounce it as [satæm] while using it in their everyday Thai conversation. Consequently, this might have an impact on their syllable identification. This area was truly worth investigating whether they realize the term "scan" consists of an initial consonant cluster [sk-] or not. In the final part or Part E (Questions 17-20), the questions asked the participants to make a comparison between listening and speaking skills. They did not have a definite answer as to whether their listening skill was better than their speaking one. As mentioned earlier, the second part of the questionnaire (Part F from questions 21-24) was designed to gain qualitative data findings. The participants wrote their answers with reasons to support their opinions. It appeared that twenty-five participants chose Phonetics and Phonology Course as the most powerful course to enhance their pronunciation skill. It laid down a strong basis in how to pronounce the words. As one of them reacted:

"Phonetics and Phonology Course provides us an opportunity to learn how to pronounce English words correctly." (informant 17)

Seven of them believed that Conversation Course improved their listening skill the most. Other courses were Conversation and Oral Presentation and Public Speaking since the contents of the courses required the participants to speak and listen to the dialogs in the textbook which were beneficial to them as well. When asked to identify the factors that enhanced both skills, the participants showed the interrelationship between the two skills. That is, to practice speaking English very often was at the top of the list when wanting to have better speaking skills. But watching movies or news and listening to music assist them in having a better skill as well. By the same token, when intending to improve listening skill, their choices revealed watching TV, news, movies. As one of them reacted:

"Listening to the English songs and news helps improve listening skill. Whenever one listen to songs and news every day, s/he will get used to it and then understand the contents." (informant 16) 
Some of the participants claimed that if they understood what people said, they could learn how to speak to convey the message to the hearers. Thus, the interrelationship between both skills was found. In other words, when they practiced one, it helped the other. They went hand in hand. A very surprising finding in Part F was the influence of the Phonetics and Phonology Course. This course was mentioned in all four questions as to whether it was an excellent course to guide the learners how to pronounce the words correctly and help their listening skill, and it was claimed that its body of knowledge was regarded as a factor in improving their listening and speaking performance as well. More precisely, four participants stated that this course bettered their pronunciation skill. Nine participants identified that what they learned from the course helped their listening skill as well.

\section{Conclusion and Suggestions}

This study set out to determine the competence of Thai speakers when dealing with English onset and coda clusters, which have longer consonant sequences. The results showed that there was no statistically significant difference in the pretest and posttest. The quantitative findings reflected that even though many marked clusters were still problematic for Thais and the Theory of Markedness could account for them, it appears that the findings were still unclear why certain marked clusters did not reflect any difficulty. This study also employed a questionnaire to elicit students' opinions about their speaking and listening performance, the courses they took in four years, and the factors that improved both skills. In an overall picture, the Thai participants revealed positive opinions about their listening and speaking performance. But they still had some problem in identifying English consonant clusters. This might cause them to misidentify some tokens on the test. In addition, they had positive reactions to many English courses they took in a four-year course of study.

Last but not least, to establish a greater degree of accuracy on English consonant clusters future studies should employ more research instruments to provide more qualitative information or findings. In other words, it would be pertinent if future studies included an interview to elicit additional or in-depth information from the participants. For example, in certain tokens, as in the term 'glimpsed' in this study, the researchers could have asked them why they performed well in the pretest, but the scores dropped in the posttest. The interview can elicit in-depth information into how they handle some problematic consonant clusters or some consonant clusters which revealed outstanding scores in both tests even though they were marked or did not exist in Thai. As stated earlier, the researcher posits that the Thai participants might have been familiar with some tokens since they were found in their everyday conversation or even textbooks. To prevent this kind of situation or to remove word or token familiarity, future studies should use pseudo tokens or nonsense words to elicit the participants' performance.

\section{Acknowledgments}

The research reported here has been fully supported by a grant from Division of Research Administration, Naresuan University, Thailand (a research project ID number: R2559C126) in the fiscal year 2016. The author wish to thank Mr. Richard Glover for his sound record, proofreading, and assistance. Special thank goes to all thirty-three students who took part in this study. Their time, patience, and coorperation are highly appreciated.

\section{References}

Chakma, S. (2014). Difficulty in pronunciation of certain English consonant sounds. Sripatum Chonburi Journal, 10(3), 110-118.

Chen, S. (2003). Acquisition of English onset clusters by Chinese learners in Taiwan. Paper presented at the Linguistics and English Language Postgraduate Conference. University of Edinburgh. Retrieved from http://www.lel.ed.ac.uk/ pgc/archive/2003/proc03/Szu-wei_Chen03.pdf

Choi, J. (2016). Investigation into Korean EFL learners' acquisition of English /s/ + consonant onset clusters. Advances in Language and Literary Studies, 7(2), 48-54.

Chunsuvimol, B. (1996). Social variation of /1/ in Thai, in The Fourth International Symposium on Language and Linguistics, Thailand, pp. 2030-2042. Institute of Language and Culture for Rural Development, Mahidol University.

Eckman, F. (1977). Markedness and the Contrastive Analysis Hypothesis. Language Learning, 27(2), 315-330. https://doi.org/10.1111/j.1467-1770.1977.tb00124.x

Estela Martinez Jurado, M. (2005). A study on the acquisition of English consonant clusters by Spanish students. INTERLINGÜÍSTICA, 16(2), 749-761.

Kalra, R. (2010). Initial consonant clusters' pronunciation problem. Galaxy: The IELE Journal, 2(1). (October 
2010),

$22-28$.

Retrieved

from

http://repository.au.edu/bitstream/handle/6623004553/13707/galaxy-iele-v2-n1-5-oct-10.pdf?sequence=1

Ladeforged, P., \& Maddieson, I. (2005). The sounds of the world's languages. USA: Blackwell Publishing.

Likitrattanaporn, W. (2014). Teaching phonological accuracy and communicative fluency at Thai secondary schools. English Language Teaching, 7(2), 1-10. https://doi.org/10.5539/elt.v7n2p1

Mano-Im, R. (1999). Pronunciation of English final consonant clusters by Thai speakers. (Unpublished MA thesis). Chulalongkorn University, Thailand.

Munro, M. (2008). Chapter 7: Foreign accent and speech intelligibility. In G. Hanson Edwards, \& M. L. Zampini (Eds), Phonology and Second Language Acquisition (pp. 193-218). Amsterdam/Philadelphia: John Benjamins Publishing Company.

Padibat, N., \& Cochran, C. (1997). An investigation of sonority dispersion in Thai-English interlanguage Codas. In S. Buchner (Ed). Working Papers in Linguistics. George Mason University. Fairfax, Virginia. (4), Spring. $5-22$.

Phoprai, S. (2008). A study on the effect of using language games to solve problems with English word final clusters of two consonant sounds of Mathayomsuksa I students at Debsirin Nonthaburi School. (Unpublished Master's project). Srinakharinwirot University. Thailand.

Phootirat, P. (2012). Register variation in Thai-English interphonology: The contrast of $/ r /$ and $/ l /$. (Unpublished docteral dissertation). The University of Wisconsin-Milwaukee, USA.

Pulsup, S. (1993). Stylistic variation of (r) and (l) in Bangkok Thai consonant clusters among Mathayom IV girl students at Sriayudhya School. (Unpublished MA thesis). Chulalongkorn University, Thailand.

Reynolds, A. R. (2011). Competing factors in phonological learning models: the acquisition of English consonant clusters. (Unpublished MA thesis). The University of North Carolina at Chapel Hill. USA.

Rungruang, A., \& Glover, R. (2017). English consonant cluster perception by L2 Thai speakers. Paper presented at the 2017 Payap University Research Symposium. Chiangmai, Thailand.

Sarapan, C. (1990). A study of English consonant pronunciation problems by Mathyom 3 students at Kamalasai School, Kalasin province. (Unpublished MA thesis). Mahasarakham University, Thailand.

Strange, W., \& Shafter, V. L. (2008). Chapter 6: Speech perception in second language learners: The re-education of selective perception. In G. H. Edwards, \& M. L. Zampini (Eds), Phonology and Second Language Acquisition (pp.153-192). Amsterdam/Philadelphia: John Benjamins Publishing Company. https://doi.org/10.1075/sibil.36.09str

Wiltshire, C. R. (2006). Word-final Consonant and Cluster Acquisition in Indian English(es). In D. Bamman, T. Magnitskaia, \& C. Zaller (Eds), On-line Proceedings supplement, 30th Boston University Conference on Language Development (pp. 1-10). Available at: http://www.bu.edu/linguistics/BUCLD/supp30.html

Yoo, H. (2004). A longitudinal study of consonant cluster acquisition. Studies in Phonetics, Phonology and Morphology, 10(3), 481-503.

Yuliati. (2014). Final consonant clusters simplification by Indonesian aearners of English and its intelligibility in international context. International Journal of Social Science and Humanity, 4(6), 513-517. https://doi.org/10.7763/IJSSH.2014.V4.409

Zampini, M. L. (2008). Chapter 8: L2 speech production research: Findings, issues, and advances. In G. Hanson Edwards \& M. L. Zampini (Eds), Phonology and Second Language Acquisition (pp. 219-250). Amsterdam/Philadelphia: John Benjamins Publishing Company. https://doi.org/10.1075/sibil.36.11zam

\section{Notes}

Note 1. Only one study by Likitrattanaporn (2014) was carried out with Thai high school teachers about their opinions in phonological accuracy practice, communicative fluency activities, authentic teaching techniques and appropriate ways to solve the problems of phonological teaching and communicative English language teaching in Thailand. 


\section{Appendix A. A sample of answer sheet in the perception tests (pretest and posttest).}

Instruction: Listen and choose the best choice. Each item will be read twice.

1. (prey)
a. prey
b. pay
c. clay
d. gray

2. (gray)
a. play
b. pay
c. clay
d. gray

3. (pupil)

a. pimple

b. purple

c. pupil

d. people

160. (thousandths)
a. thousand
b. thousandths
c. thousandth
d. thousands

Appendix B. Questionnaire score report

\begin{tabular}{|c|c|c|c|c|}
\hline Parts & Question Number & Mean & S.D. & Interpretation \\
\hline \multirow{4}{*}{$\begin{array}{l}\text { A } \\
\text { (Speaking's skill) }\end{array}$} & 1 & 4.12 & 0.60 & agree \\
\hline & 2 & 3.58 & 0.75 & agree \\
\hline & 3 & 4.21 & 0.89 & Strongly agree \\
\hline & 4 & 4.03 & 0.73 & Agree \\
\hline \multirow{4}{*}{$\begin{array}{l}\text { B } \\
\text { (Listening's skill) }\end{array}$} & 5 & 4.24 & 0.71 & Strongly agree \\
\hline & 6 & 3.27 & 0.88 & Uncertain \\
\hline & 7 & 3.58 & 1.06 & Agree \\
\hline & 8 & 3.85 & 0.62 & Agree \\
\hline \multirow{4}{*}{$\begin{array}{l}\text { C } \\
\text { (English courses) }\end{array}$} & 9 & 4.48 & 0.57 & Strongly agree \\
\hline & 10 & 4.24 & 0.66 & Strongly agree \\
\hline & 11 & 4.30 & 0.77 & Strongly agree \\
\hline & 12 & 1.64 & 0.82 & Strongly disagree \\
\hline \multirow{4}{*}{$\begin{array}{l}\text { D } \\
\text { (English } \\
\text { structure) }\end{array}$} & 13 & 3.55 & 0.56 & Agree \\
\hline & 14 & 3.79 & 0.86 & Agree \\
\hline & 15 & 2.76 & 1.64 & Uncertain \\
\hline & $16^{*}$ & 2.52 & 1.60 & Disagree \\
\hline \multirow{4}{*}{$\begin{array}{l}\text { E } \\
\text { (Relationship } \\
\text { between speaking } \\
\text { and listening) }\end{array}$} & 17 & 4.21 & 0.78 & Strongly agree \\
\hline & 18 & 4.03 & 0.73 & Agree \\
\hline & 19 & 3.30 & 0.88 & Uncertain \\
\hline & 20 & 2.82 & 0.88 & Uncertain \\
\hline
\end{tabular}

*In question 16 (The words "bet" and "best" does not share the same number of syllables), the reverse wording of questionnaire items was employed. It refers that the participants agreed that "bet" and "best" shared the same number of syllables. 


\section{Appendix C. Part F (questions 21-24) from questionnaire.}

The reasons in the text form in each question item were excluded here.

\begin{tabular}{|c|c|}
\hline 21. In your opinion, what English course betters your pronunciation skill the most? Why? & Frequency \\
\hline - $\quad$ Phonetics and Phonology & 25 \\
\hline - Conversation and Discussion & 7 \\
\hline - $\quad$ Oral Presentation and Public Speaking & 5 \\
\hline - $\quad$ Basic Oral Skill & 1 \\
\hline - $\quad$ English for Hotel Business & 1 \\
\hline \multicolumn{2}{|l|}{$\begin{array}{l}\text { 22. What major factors better your pronunciation skill? Why? (Your answer can be } \\
\text { multiple/ your answer can be more than one.) }\end{array}$} \\
\hline - $\quad$ Practice (speaking) & 12 \\
\hline - $\quad$ Communicate with native speakers or foreigners & 9 \\
\hline - $\quad$ See movie and listen music & 9 \\
\hline - $\quad$ Talk to native speakers & 9 \\
\hline - $\quad$ Listen native speaker dialog or conversation & 5 \\
\hline - $\quad$ Have phonetic knowledge & 4 \\
\hline - $\quad$ Listen to news & 4 \\
\hline - Use online dictionaries that have phonetic symbols & 3 \\
\hline - $\quad$ Read a lot & 3 \\
\hline \multicolumn{2}{|l|}{ 23. In your opinion, what English course betters your listening skill the most? Why? } \\
\hline - Conversation & 17 \\
\hline - $\quad$ Oral Presentation and Public Speaking & 4 \\
\hline - $\quad$ Phonetics and Phonology & 4 \\
\hline - $\quad$ Business 1 and 2 & 2 \\
\hline \multicolumn{2}{|l|}{$\begin{array}{l}\text { 24. What factors better your listening skill? Why? (Your answer can be multiple/ your } \\
\text { answer can be more than one.) }\end{array}$} \\
\hline - Watch movies & 15 \\
\hline - $\quad$ Have phonetic knowledge & 9 \\
\hline - $\quad$ Practice listening very often & 8 \\
\hline - $\quad$ Listen to music & 5 \\
\hline - Have vocabularies in your brain & 2 \\
\hline
\end{tabular}

\section{Copyrights}

Copyright for this article is retained by the author(s), with first publication rights granted to the journal.

This is an open-access article distributed under the terms and conditions of the Creative Commons Attribution license (http://creativecommons.org/licenses/by/4.0/). 